\title{
Són útils les WebQuests per desenvolupar els continguts del currículum de Física i Química?
}

\author{
Carmen Fernández Hierro \\ IES Salvador Dalí (El Prat de Llobregat) \\ cfernand@.xtec.es
}

Es tracta de mostrar, mitjançant enllaços a exemples de WebQuests de ciència, l'estructura generalitzada que s'hi fa servir per presentar la informació. Al mateix temps, es fa una reflexió personal sobre la possible adequació d'aquest tipus d'activitats en l'ensenyament de la Física i la Química en la Secundària.

A partir de la meva experiència com a autora novella de WebQuests, aquest escrit pretén fer una reflexió sobre aquest recurs, amb un objectiu concret: desenvolupar els continguts del currículum de quart d'ESO.

Em vaig apropar a aquesta metodologia pensant que em serviria per organitzar i utilitzar de manera més eficient els recursos de la xarxa i de les noves tecnologies, tecnologies que fa temps que faig servir, encara que d'una manera no sempre totalment planificada. Acostumada a desenvolupar els treballs pràctics de laboratori dins d'una seqüència de cicle d'aprenentatge, vaig trobar cert paral-lelisme entre la manera ordenada de fer de les WebQuests i el model que faig servir a les experiències de laboratori. En aquestes pràctiques es presenta una situació, es fan unes prediccions sobre els resultats que es pensen obtenir, es realitzen les mesures necessàries per discutir els resultats a partir de les prediccions fetes i finalment s'intenten aplicar les conclusions a noves situacions.

A mesura que he conegut més exemples de WebQuests he pogut aprofundir-hi. Tot i sent conscient del seu potencial, actualment tinc el dubte de si és possible construir una bona WebQuest per a desenvolupar i aprofundir els conceptes i procediments del currículum de Física i Química (forces, canvis d'estat, interpretació de gràfics,...), o més aviat són d'utilitat per desenvolupar els objectius generals del currículum (coneixement de l'evolució cientificotecnològica de la societat, anàlisi crítica de la informació, treball en grup...).

Però abans de continuar la reflexió descriuré què són les WebQuests, com s'utilitzen i faré refe- rència a alguns enllaços, que crec que poden ser d'interès.

\section{QUĖ SÓN LES WEBQUESTS?}

Les WebQuests neixen als anys noranta (1995) de la mà de Bernie Dodge i Tom March de la Universitat Estatal de San Diego amb la idea de dirigir l'alumnat, amb objectius clars i ben definits, perquè utilitzi profitosament el gran potencial que té la navegació per Internet.

Des d'aleshores, és tan gran el desplegament d'informació repetida, transformada i traduïda que hi ha a la xarxa referent a les WebQuests, que abans de tot és necessari esmentar les fonts originals. Adreceu-vos a The WebQuest Page i WebQuests \& more, on es poden trobar articles $\mathrm{i}$ exemples seleccionats i classificats. D'altra banda, a la revista electrònica Quaderns digitals.net, també s'hi pot trobar un interessant monogràfic sobre el tema.

Crec que l'objectiu fonamental d'aquest tipus d'activitats és que l'alumne aprengui a seleccionar les dades de fonts diverses i desenvolupi el seu pensament crític. Les paraules claus que utilitza la metodologia són: transformar la informació per construir el propi coneixement i desenvolupar en l'alumnat un pensament d'alt nivell (sintetitzar, analitzar, comprendre, valorar, jutjar...).

Com ja he comentat abans, actualment hi ha molta informació a la xarxa que tracta d'explicar els conceptes bàsics de la metodologia i posa a l'abast dels docents diversos tipus de plantilles per desenvolupar els diferents components. Així doncs, la tasca tècnica que ha de fer el professorat per es- 
tructurar la informació es redueix considerablement quan s'utilitzen aquestes plantilles. El gran repte dels autors i autores és omplir amb continguts engrescadors i eficaços els diferents components de la WebQuest.

Per analitzar aquests components faré servir enllaços a Paper Airplane Exploration, una WebQuest adreçada a alumnes amb edats similars als del segon cicle de secundària: una WebQuest de presentació senzilla que pot ajudar a descriure les diferents parts de la seva estructura.

De manera força generalitzada la informació es presenta als alumnes fent servir els següents apartats:

- Introducció. Situa el problema i dóna algun tipus d'informació general. És l'escenari que prepara l'acció a desenvolupar.

- Tasca. Explica el producte final que han d'obtenir els estudiants. És important que la tasca sigui assequible i interessant.

- Procés. Descriu el camí a seguir per obtenir el producte que es demana.

- Recursos. Selecciona els recursos que 'alumne necessita per realitzar la tasca encomanada. L'apartat està vinculat als dos apartats anteriors. De fet, hi ha WebQuests on no es separen els recursos de la tasca o del procés.

- Avaluació. S'informa a l'alumne de com serà avaluat.

- Conclusió. Es fa una reflexió sobre què s'ha fet, i s'intenta donar una aplicació o bé una continuïtat al que s'ha après.

Degut al fet que cada autor o autora posa l'èmfasi on considera que la metodologia pot ser més profitosa, es poden analitzar presentacions diverses. Trobem exemples on es dóna molta importància al treball cooperatiu i cada component del grup de treball assumeix un paper amb diferents comeses (vegeu Roller Coaster Madness o bé Vibraciones y ondas). En canvi, n'hi ha d'altres on s'esmenta que s'ha de treballar en grup però no es distribueixen tasques diferenciades (vegeu, per exemple, Genètica humana) i en cap moment queda descartat un desenvolupament individual del treball (vegeu Some Thoughts About WebQuests). De fet, organitzar grups i distribuir funcions no és un atribut essencial de la WebQuest, malgrat que en la pràctica ha esdevingut també un objectiu important en molts dels casos.

\section{PER A QUÈ SERVEIXEN LES WEBQUESTS?}

Buscant en diferents portals d'Internet on hi ha exemples i recopilacions sobre el tema, he estat observant que la major part de les activitats proposades a l'estudiant sobre ciència, i en concret sobre Física i Química, tenen les següents característiques:

- Generalment són propostes d'investigació, aplicació o ampliació dels continguts (Sistema Solar, la quiralitat, tren de levitació magnètica, el Radó,...)

- Estan relacionades amb temes científics d'actualitat que han donat lloc a certa polèmica social (aliments genèticament modificats, energies renovables, reproducció assistida, contaminació ambiental...)

- Normalment, la tasca a realitzar té a veure amb la construcció d'un objecte o amb la producció d'un document (pàgina Web, PowerPoint, document Word...) que serveix de suport a una exposició pública de les conclusions.

- L'avaluació es sol centrar en la part del currículum corresponent als objectius generals i als continguts de procediments.

Sembla, doncs, que aquestes activitats didàctiques es podrien utilitzar, en major mesura, per omplir la part del currículum que normalment es deixa de banda en la pràctica docent comuna de les Ciències Experimentals, i que es cobreix amb les activitats dels crèdits variables, les optatives de batxillerat, els treballs de recerca o amb les jornades o setmanes de ciència que s'organitzen als IES.

La presentació de situacions d'aplicació tecnològica o el plantejament de problemes oberts i polèmics amb possible assignació de tasques especifiques als diferents components del grup, sembla una manera interessat i útil d'abordar objectius generals del currículum de Física i Química, com per exemple:

- Comprendre a grans trets l'evolució cientificotecnològica de la nostra societat.

- Buscar informació en diferents fonts, molt especialment a través de les tecnologies de la informació i de la comunicació, i avaluar-ne després la idoneïtat.

- Expressar oralment i per escrit les observacions realitzades.

- Actuar de forma que s'afavoreixi la sostenibilitat de les formes de vida i del medi ambient, cosa que implica anàlisi, avaluació, imaginació creativa, negociació, cooperació i execució d'accions individuals i col-lectives.

- Valorar actituds científiques com la curiositat, l'objectivitat, el rigor, l'esperit crític, la perseverança i el treball en equip per qüestionar-se les pròpies idees i conclusions, buscar evidències $i$ utilitzar-les en l'argumentació. 
Però no és tan clar, i hi ha pocs exemples per analitzar, si les WebQuests són també útils per desenvolupar la part del currículum relativa als conceptes i procediments més específics de l'àrea, o per veure si és possible abordar tots els objectius a l'hora, ja que seria bo no separar els conceptes bàsics de les aplicacions tecnològiques i de les seves repercussions socials.

A tall d'exemple, la WebQuest per a segon de Batxillerat, sobre vibracions i ones (Fernández, J., Ortega, M., Real, J.) és la que més s'ajusta, d'entre les que he trobat, al desenvolupament de conceptes i procediments del currículum; en aquest cas, per a la Física de segon de Batxillerat. Mitjançant la web s'assignen diferents tasques i rols als estudiants perquè construeixen el seu coneixement $a$ partir d'applets i de diversos llocs web especificats a l'apartat de recursos. Als alumnes se'ls demana que facin els seus propis apunts, que dissenyin un treball experimental i que creïn un document web per exposar a classe les seves conclusions. A més, durant el desenvolupament de l'activitat han de lliurar un conjunt d'exercicis resolts i presentar altres exercicis que hauran de resoldre la resta de companys. Evidentment, si els alumnes surten airosos d'aquesta empresa i són capaços de plantejar i resoldre problemes adients sobre les ones i vibracions, segurament hauran desenvolupat alts nivells de pensament i augmentat considerablement els seus coneixements. Caldria saber, però, quants alumnes n'han estat capaços, i quan de temps han necessitat per dur a terme l'activitat.

Tinc força més clar que utilitzar aquest tipus d'activitats d'investigació per abordar dins de l'ESO els conceptes i els procediments que se'ns demanen, requereix, al meu entendre, una aplicació de la metodologia molt pautada i molt interactiva. No només amb l'ordinador i entre els estudiants, sinó entre el professorat i l'alumnat. Potser seria necessari fer activitats prèvies curtes i molt dirigides, amb els recursos de la xarxa molt ben seleccionats, i sempre amb la condició que els recursos existents al laboratori i a la classe fossin realment importants. Aquest tipus d'activitats serien una mena de tutorial interactiu amb l'estructura de les WebQuest, amb les quals es podria aprofitar tot el potencial de la xarxa i tot el desenvolupament que s'ha fet de la metodologia. Però ens podríem preguntar si serien veritablement unes WebQuests.

\section{ALGUNES REFLEXIONS}

L'experiència didàctica del professorat de secundària de Física i Química està basada principalment en el desenvolupament dels conceptes (força, pressió, molècula,..) i en els procediments més propis de la disciplina, com treball experimen- tal, resolució de problemes i interpretació de gràfiques.

Tothom sap que adquirir competència en aquests continguts és una tasca que porta temps, que involucra pensament d'alt nivell i requereix una continuada anada i tornada per part de l'estudiant. Aquestes habilitats són les que, de moment, i malgrat els objectius més generals, s'avaluen externament, i són les que resulten més difícils d'assolir dins d'un ensenyament generalitzat.

No és estrany un desenvolupament de la metodologia en els aspectes més socials de la disciplina. Per això, el dubte que es planteja és el següent: ara que es parla tant de WebQuests, hem de saber si són adequades per a l'ensenyament que se'ns demana, amb tot el currículum a la mà, al professorat de Física i Química.

\section{ADRECES D'INTERÈS SOBRE WEBQUESTS}

http://webquest.sdsu.edu/webquest.html. Pàgina de Bernie Dodge, creador de les WebQuest, amb exemples, articles i informació general sobre elles.

http://www.ozline.com/learning. Aportacions de Tom March al desenvolupament de les WebQuests, i informació sobre la interacció entre web i educació.

http://www.xtec.es/ cbarba1/. Pàgina personal de Carmen Barba amb classificació en Llengua Catalana i Llengua Castellana de WebQuests per àrees i nivells educatius.

http://www.cpr2valladolid.com:8080/BDWQ/Biblio.a spx. Base de dades de Santiago Blanco per cerca WebQuest.

http://www.aula21.net. Pàgina de Francisco Muñoz, amb informació sobre WebQuests, conté molts exemples i enllaços.

\begin{tabular}{l}
\hline http://www.quadernsdigitals.net/index.php?accionM \\
\hline e- \\
hu=hemeroteca.VisualizaNumeroRevistalU.visualiz \\
\hline a\&numeroRevista id=527. Quaderns digitals, mo \\
\hline nogràfic sobre WebQuests.
\end{tabular}

http://platea.pntic.mec.es/ -jerna5/. Pàgina de José Julio Real i José Fernández sobre investigació educativa a Internet amb recursos sobre WebQuests.

http://www.eduteka.org/webquest.php3. Portal educatiu de Colòmbia de la fundació Gabriel Piedrahita Uribe, amb exemples de WebQuests en castellà. Articles traduïts de l'original. 